\title{
Inhibition of IncRNA NEAT1 suppresses the inflammatory response in IBD by modulating the intestinal epithelial barrier and by exosome-mediated polarization of macrophages
}

\author{
RUI LIU ${ }^{1-3}$, ANLIU TANG ${ }^{1-3}$, XIAOYAN WANG ${ }^{1-3}$, XIONG CHEN $^{1-3}$, \\ LIAN ZHAO ${ }^{1-3}$, ZHIMING XIAO ${ }^{1-3}$ and SHOURONG SHEN ${ }^{1-3}$ \\ ${ }^{1}$ Department of Gastroenterology, The Third Xiangya Hospital of Central South University; \\ ${ }^{2}$ Hunan Key Laboratory of Nonresolving Inflammation and Cancer; \\ ${ }^{3}$ National Key Clinical Specialty, Changsha, Hunan 410013, P.R. China
}

Received February 10, 2018; Accepted July 24, 2018

DOI: $10.3892 /$ ijmm.2018.3829

\begin{abstract}
Inflammatory bowel disease (IBD) is a multifactorial inflammatory disease, and increasing evidence has demonstrated that the mechanism of the pathogenesis of IBD is associated with intestinal epithelial barrier injury. Long non-coding RNAs (lncRNAs) are a class of transcripts $>200$ nucleotides in length with limited protein-coding capability. Nuclear paraspeckle assembly transcript 1 (NEAT1) is a recently identified nuclear-restricted lncRNA, which localizes in subnuclear structures, termed paraspeckles, and is involved in the immune response in a variety of ways. However, the function of NEAT1 in IBD remains to be fully elucidated. In the present study, reverse transcription-quantitative polymerase chain reaction assays were performed to determine the expression levels of NEAT1 lncRNA in IBD serum samples and tissues. Furthermore, the effect of NEAT1 on the cell permeability of colon cells was investigated via determination of trans-epithelial electrical resistance as well as performance of western blot and immunofluorescence assays. In addition, dextran sodium sulfate assays were performed to investigate the effect of downregulation of NEAT1 in IBD of mice. The present study detected the expression levels of NEAT1 in IBD cells and animal models to examine the changes in intestinal epithelial cell permeability following inhibition of the expression of NEAT1. In addition, phenotypic transformation was examined following different treatments in epithelial cells and macrophages. The results suggested that the expression
\end{abstract}

Correspondence to: Ms. Shourong Shen, Department of Gastroenterology, The Third Xiangya Hospital of Central South University, 138 Tong Zi Po Road, Yuelu, Changsha, Hunan 410013, P.R. China

E-mail: shenshourong_csu@163.com

Key words: inflammatory bowel disease, intestinal epithelial barrier, nuclear paraspeckle assembly transcript 1, macrophage, exosomes of NEAT1 was high in IBD and was involved in the inflammatory response by regulating the intestinal epithelial barrier and through exosome-mediated polarization of macrophages. The downregulation of NEAT1 suppressed the inflammatory response by modulating the intestinal epithelial barrier and through exosome-mediated polarization of macrophages in IBD. The results of the present study revealed a potential strategy of targeting NEAT1 for IBD therapy.

\section{Introduction}

Inflammatory bowel disease (IBD) is multifactorial inflammatory disease, the most common forms of which include Crohn's disease and ulcerative colitis. IBD is a complex autoimmune disease, which is associated with genetic predisposition, intestinal epithelial barrier injury, intestinal flora and adaptive immunity, however, the pathogenic mechanisms involved in the development and progression of IBD remain to be fully elucidated (1). Increasing evidence has demonstrated that IBD is an intestinal barrier disease and that injury of the intestinal barrier usually results in disease occurrence $(2,3)$. Although advances in therapeutic strategies have been achieved using glucocorticoids, due to differences between individuals, diverse levels of effectiveness and the side effects of treatment confound IBD therapy. Therefore, it is necessary to develop novel strategies for more effective diagnosis and treatment of IBD.

Long non-coding RNAs (lncRNAs) are a class of transcripts $>200$ nucleotides in length with limited protein-coding capability. The human genome encodes $\sim 10,000$ lncRNA genes (4); lncRNAs have significant roles in differentiation, proliferation, apoptosis and various biological processes by serving as regulatory factors for gene expression. lncRNAs have been found to be tightly linked to a diverse range of human diseases, including IBD (5). For example, the overexpression of IncRNA H19 was found to increase Caco-2 monolayer permeability and decrease the expression of tight junction proteins by increasing the expression of microRNA (miR)-675, ultimately causing the destruction of intestinal epithelial barrier function (6). Nuclear paraspeckle assembly 
transcript 1 (NEAT1) is a recently identified nuclear-restricted lncRNA, which localizes exclusively in subnuclear structures, termed paraspeckles, and serves as an essential architectural component $(7,8)$. Accumulating evidence has suggested that NEAT1 may be crucial in regulating gene expression and consequently influence physiological and pathophysiological processes (9). Previous studies have reported that NEAT1 is associated with several types of cancer, including breast cancer (7), prostate cancer $(10,11)$, acute promyelocytic leukemia (12) and colorectal cancer $(13,14)$, by promoting tumor growth through genetic or epigenetic mechanisms. In addition, NEAT1 is a key component for establishing the ribonucleoprotein complex to regulate of DNA-mediated activation of the innate immune response (15). NEAT1 was also revealed to be associated with the innate immune response, and it may function as a regulatory factor of inflammatory cytokines (16). However, to date, there have been few reports on the role of NEAT1 in IBD, and investigations of the expression pattern and clinical significance of NEAT1 in IBD are warranted.

Previous investigations (17-21) showed that the knockdown of NEAT1 impaired the integrity and increased the permeability of the blood-tumor barrier, accompanied by the downregulation of the expression of the tight junction proteins Zonula occludens-1 (ZO-1), Occludin and Claudin-5 in glioma endothelial cells. In addition, these results suggested that NEAT1 is important in regulating the permeability of the blood-tumor barrier. An ineffective intestinal epithelial barrier is usually regarded as a significant cause of IBD. Therefore, it was hypothesized that NEAT1 may regulate the permeability of epithelial cells and that an imbalance in the expression of NEAT1 may be present in IBD.

Exosomes are 40-150 $\mathrm{nm}$ microvesicles secreted by various cell types via the endosomal compartment in multivesicular bodies and thus express endosomal markers, including CD9, CD61 and Heat-shock protein (Hsp)90// (22). Exosomes belong to a group of naturally secreted extracellular vesicles, which mediate short- and long-distance intercellular communication and deliver different types of biologically active cargo to recipient cells $(23,24)$. In addition, exosomes are involved in other biological processes, including material transportation, cell division and apoptosis, and circulating exosomes have been demonstrated to be involved in regulation of the immune response (25). Exosomes have also been confirmed to be involved in the pathogenesis of IBD through the modulation of p38 and extracellular signal-regulated kinase (ERK) phosphorylation and the production of tumor necrosis factor- $\alpha$ to regulate macrophage activity (26).

As several studies have reported that NEAT1 is tightly connected to the inflammatory response, in the present study, it was hypothesized that the expression of NEAT1 in IBD is imbalanced, and that this imbalance may ultimately induce intestinal epithelial barrier injury. In addition, it was hypothesized that the imbalance in the expression of NEAT1 may occur through exosome delivery, which is an important intermediary in the crosstalk between epithelial cells and macrophages. In the present study, the expression levels of NEAT1 were detected in IBD cells and animal models, and the change in intestinal epithelial cell permeability following the inhibition of IncRNA NEAT1 expression was examined. The molecular mechanisms by which NEAT1 mediates the inflammatory response were also investigated. The results of the present study may reveal a potential strategy of targeting NEAT1 for IBD therapy.

\section{Materials and methods}

Cell culture. RAW264.7 cell lines were purchased from the Type Culture Collection of the Chinese Academy of Sciences (Shanghai, China) and cultured in 1640 culture medium (Gibco; Thermo Fisher Scientific, Inc., Waltham, MA, USA) plus $10 \%$ fetal bovine serum (FBS; Gibco; Thermo Fisher Scientific, Inc.) at $37^{\circ} \mathrm{C}$. The HT-29 colon cancer cell line and the NCM460 normal immortalized colon epithelial cell line, which represents a reliable model of the human intestine, were obtained from the Cell Center of Xiangya School of Medicine, Central South University (Hunan, China). The cells were routinely cultured in high glucose DMEM (Gibco; Thermo Fisher Scientific, Inc.) with 10\% FBS (Gibco; Thermo Fisher Scientific, Inc.) at $37^{\circ} \mathrm{C}$ in an incubator with a humidified atmosphere containing $5 \% \mathrm{CO}_{2}$.

Animal experiments. All animal experiments were performed in accordance with the guidelines of the Animal Experimentation Ethics Committee of Central South University. Male C57BL/6 mice ( $\mathrm{n}=15,6$-week-old, 25-30 g and 5 mice/group) purchased from the Laboratory Animal Center of Xiangya Hospital of Central South University and housed at $25^{\circ} \mathrm{C}$ with a $12 / 12 \mathrm{~h}$ light/dark cycle, $40-70 \%$ humidity and ad libitum access to food and water. The animals were treated with $5 \%$ dextran sulfate sodium (DSS) in their drinking water for 2 weeks, following which intestinal mucosa and serum were harvested for further analysis. In addition, 6-week-old Sprague-Dawley rats $(\mathrm{n}=25$, 12 males and 13 females; Central South University) weighing $\sim 180 \pm 10 \mathrm{~g}$ (5 mice/group) were treated with 5\% DSS for 2 weeks, and 10 rats were transfected with $100 \mu \mathrm{l}$ of $293 \mathrm{~T}$ cells (titer of $1,000 \mathrm{ng} / \mathrm{p} 24)$ carrying a lentiviral vector encoding shRNA or shRNA-NEAT1 via rectal perfusion. The weight, diet, feces, and hair status of all animals were recorded. At the end of the experiments, the rats were anaesthetized and sacrificed, and whole colon tissues were harvested for further analysis.

Western blot assay. Total proteins were harvested from exosomes, HT-29, RAW264.7 and NCM460 cells or mouse colon tissues. Samples were lysed in radioimmunoprecipitation assay buffer (cat. no. P002A; Auragene, Changsha, China) containing proteinase inhibitors. Following a 20 min incubation on ice, total protein was extracted via centrifugation at $1,000 \mathrm{x} \mathrm{g}$ for $20 \mathrm{~min}$ at $4^{\circ} \mathrm{C}$. A bicinchoninic acid assay was used to determine protein concentration prior to the sample being diluted into $2 \mathrm{mg} / \mathrm{ml}$ with sodium dodecyl sulfate-loading buffer (cat. no.P003B; Auragene). Protein samples $(20 \mu \mathrm{g})$ were subsequently separated by $12 \%$ SDS-PAGE and transferred onto polyvinylidene fluoride membranes by electroblotting. The membranes were blocked with 5\% non-fat milk and then probed with primary antibodies against the following proteins at $4^{\circ} \mathrm{C}$ overnight: $\mathrm{CD} 9$ (cat. no. ab92726; 1:2,000; Abcam, Cambridge, UK), Hsp90 $\alpha / \beta$ (cat. no. ab203126; 1:10,000; Abcam), ZO-1 (cat. no. ab96587; 1:2,000; Abcam), Claudin-5 (cat. no. ab131259; 1:5,000; Abcam), Occludin (cat. no. ab222691; 1:500; Abcam), Interleukin (IL)23 (cat. 
no. ab190356; 1:1,000; Abcam), Inducible nitric oxide synthase (iNOS; cat. no. ab204017; 1:1,000; Abcam), IL10 (cat. no. ab34843; 1:500; Abcam), Arginase-1 (cat. no. ab124917; 1:5,000; Arg-1; Abcam), CD206 (cat. no. ab64693; 1:4,000; Abcam) and $\beta$-actin (cat. no. ab8226; 1:15,000; Abcam). This was followed by incubation with HRP-conjugated anti-mouse IgG antibodies (cat. no. a5278; 1:15,000; Sigma-Aldrich; Merck KGaA, Darmstadt, Germany) at room temperature for $40 \mathrm{~min}$. Finally, the immunosignals were visualized using chemiluminescence reagents following exposure to X-ray film, and the expression levels of target proteins were analyzed using Image J software (version 1.80; Bio-Rad Laboratories, Inc., Hercules, CA, USA).

Reverse transcription-quantitative polymerase chain reaction (RT-qPCR) analysis. Total RNA was extracted using TRIzol (Invitrogen; Thermo Fisher Scientific, Inc.) and then analyzed via RT-qPCR analysis using the Real-Time Quantitative PCR SYBR-Green detection reagent (Takara Bio, Inc., Tokyo, Japan) according to the manufacturer's protocol. RT was performed using cDNA $(1.0 \mu \mathrm{l})$, $\mathrm{ddH}_{2} \mathrm{O}(7.0 \mu \mathrm{l})$, forward primers $(10 \mu \mathrm{mol} / \mathrm{l})$ and reverse primers $(10 \mu \mathrm{mol} / \mathrm{l})$. The temperature protocol used to perform RT was $42^{\circ} \mathrm{C}$ for $1 \mathrm{~h}$ followed by $70^{\circ} \mathrm{C}$ for $10 \mathrm{~min}$. The fluorophore used for qPCR was $2 \mathrm{X}$ SYBR-Green PCR Mix (Bio-Rad Laboratories, Inc.) and the thermocycling conditions used were as follows: Initial denaturation at $95^{\circ} \mathrm{C}$ for $3 \mathrm{~min}$; followed by 40 cycles denaturation at $95^{\circ} \mathrm{C}$ for $10 \mathrm{sec}$; followed by annealing/elongation at $60^{\circ} \mathrm{C}$ for $30 \mathrm{sec}$. The primer sequences were as follows: IncRNA NEAT1, forward 5'-CCAGGGTGGTGGCAGTGC-3' and reverse 5'-CCCAGCCTCAGCGGGAAG-3'; Monocyte chemoattractant protein 1 (MCP-1), forward 5'-ACTTCACCAATAGGA AGATCTCAGT-3' and reverse 5'-TGAAGATCACAGCTT CTTTGG-3'; IL-23, forward 5'-GGGACACATGGATCTAAG AG-3' and reverse 5'-CGATCCTAGCAGCTTCTCAT-3'; and $\beta$-actin, forward 5'-AGGGGCCGGACTCGTCATACT-3' and reverse 5'-GGCGGCACCACCATGTACCCT-3'. The relative expression of each target gene was calculated using the $2^{-\Delta \Delta C q}$ formula (27) relative to the expression level of $\beta$-actin.

Exosome isolation. Prior to purification of the exosomes, the blood serum supernatant was isolated from 1-1.5 ml of mouse blood, which was maintained in a low-temperature environment for $1 \mathrm{~h}$ and then centrifuged at $1,000 \mathrm{x} \mathrm{g}$ for $10 \mathrm{~min}$ at $4^{\circ} \mathrm{C}$. The exosomes were isolated using the exosome isolation reagent (Guangzhou RiboBio Co., Ltd., Guangzhou, China) according to the manufacturer's protocol with modification. Briefly, the blood serum was transferred to the tubes, and centrifuged at $3,000 \times \mathrm{g}$ for $30 \mathrm{~min}$ at $4^{\circ} \mathrm{C}$. The supernatant was then collected and filtered using a $0.22-\mu \mathrm{m}$ filtrator, and was then transferred into an ultrafiltration tube $(30-\mathrm{kDa})$, and centrifuged at $6,000 \mathrm{x} \mathrm{g}$ for $10 \mathrm{~min}$ at $4^{\circ} \mathrm{C}$. The mixture in the upper chamber was resuspended with PBS and an appropriate volume of $8 \%$ PEG6000 solution was added, followed by centrifugation at $10,000 \mathrm{x}$ g for $60 \mathrm{~min}$ at $4^{\circ} \mathrm{C}$. Finally, the precipitate was resuspended with $\mathrm{PBS}$. The expression of Hsp90 $\alpha / \beta$ and CD9 (27) in the concentrated exosome fractions was analyzed by western blot analysis, and positive expression for $\mathrm{Hsp} 90 \alpha / \beta$ and CD9 was recognized when the exosomes had been successfully obtained.
Lentivirus production and transduction. The sequence of lentiviral short hairpin (sh)RNA targeting NEAT1 was designed though Block-iTä RNAi Designer online software (http://rnaidesigner.thermofisher.com/rnaiexpress). The shRNA-NEAT1 was cloned into the apLV-H1TetO-GFP-Puro vector (Auragene) according to the manufacturer's protocol, followed by the transduction of $293 \mathrm{~T}$ cells (Auragene) with the recombinant vector. The viruses were packaged in $293 \mathrm{~T}$ cells and harvested $72 \mathrm{~h}$ later. The lentiviruses carrying shRNA-NEAT1 were termed LV-shNEAT1, and the empty lentiviral vector, termed LV-shRNA, was used as a control. The HT-29 and NCM460 cells were infected with virus particles using $6 \mu \mathrm{g} / \mathrm{ml}$ of polybrene, and the medium was replaced following $24 \mathrm{~h}$ of incubation. After $\sim 2$ days, the target cells were harvested for further analysis.

Trans-epithelial electrical resistance (TEER) measurement. The barrier properties of the HT-29 and NCM460 cells were assessed by measuring the TEER using a Millicell ${ }^{\circledR}$ ERS Multimeter (EMD Millipore) as previously described (28). The cells were seeded on Millicell hanging cell culture inserts with a $0.4-\mu \mathrm{m}$ pore size polyethylene terephthalate membrane at a density of 12,0000 cells $/ \mathrm{ml}$. Following 21 days of culture in the inserts, the HT-29 and NCM460 cell monolayer states were obtained. TEER was measured $2 \mathrm{~h}$ following replacement of the culture medium. The resistance of the cell monolayer samples measured in the assays, minus the resistance of the blank membrane insert, indicated the resistance of the intestinal cell monolayer.

Fluorescein isothiocyanate (FITC)-conjugated dextran (cat. no. 53379, FITC-dextran; Sigma; EMD Millipore) was used to detected the cell permeability. The cells were cultivated on a Transwell $\left(0.33 \mathrm{~cm}^{2}\right)$ to cell monolayers. Sterile bicarbonate-buffered Ringer's solution was used to wash the cells, following which FITC-Dextran-FITC $(100 \mu \mathrm{M})$ was added to the upper chambers for $2 \mathrm{~h}$. The basolateral chambers were collected in 96 plates, and detected using a fluorescent plate reader (cat. no. 3916, Costar; Corning Incorporated, Corning, NY, USA) with $480 \mathrm{~nm}$ excitation and 520 emission filters (29). The paracellular flux was determined from a standard curve and normalized to the negative control group.

Immunofluorescence. The cells were fixed with $4 \%$ paraformaldehyde and permeabilized using $0.2 \%$ Triton X-100 for 10 min following being grown on coated coverslips. The cells were washed three times with PBS and then blocked with $3 \%$ bovine serum albumin (Gibco; Thermo Fisher Scientific, Inc.) for $1 \mathrm{~h}$ at room temperature, followed by incubation with monoclonal anti-occludin antibody (cat. no. ab222691; 1:500; Abcam) at $4^{\circ} \mathrm{C}$ overnight. Subsequently, the cells were washed and then incubated with Alexa-conjugated secondary antibody (PV-8000; One-step universal method kit; OriGene Technologies, Inc., Rockville, MD, USA) for $1 \mathrm{~h}$ at room temperature. The cells were then counterstained with 4',6-diamidino-2-phenylindole (Invitrogen; Thermo Fisher Scientific, Inc.) at room temperature for $15 \mathrm{~min}$, and finally, the coverslips were treated with ProLong Gold antifade reagent (Thermo Fisher Scientific, Inc.), and fluorescence signals were visualized using a Leica TCS SP5 confocal microscope. 
Flow cytometry. The HT-29 and NCM460 cells $\left(5 \times 10^{5}\right.$ cells $\left./ \mathrm{ml}\right)$ transfected with $\mathrm{LV}$-shNEAT1 were harvested by trypsinization at $37^{\circ} \mathrm{C}$ following treatment with TNF- $\alpha$ for $48 \mathrm{~h}$ at $37^{\circ} \mathrm{C}$. The cells were then centrifuged at $600 \mathrm{x} \mathrm{g}$ for $5 \mathrm{~min}$ at $37^{\circ} \mathrm{C}$, washed twice using PBS and incubated with monoclonal anti-CD206 (cat. no. 12-2069-42; 1:200; Thermo Fisher Scientific, Inc.) antibody for $60 \mathrm{~min}$. The cells were washed again and incubated with FITC-conjugated secondary antibody (cat. no. 400109; 1:500; BioLegend, Inc., San Diego, CA, USA) in the dark for $60 \mathrm{~min}$ at room temperature. Finally, the cell population was washed and resuspended using PBS, following which the cells were analyzed using a flow cytometer (BD Biosciences, Franklin Lakes, NJ, USA).

Haemotoxylin and eosin (H\&E) staining assay. Tissues were immediately fixed in $10 \%$ formalin solution for $12 \mathrm{~h}$ at room temperature and embedded in paraffin. Embedded paraffin blocks were subsequently cut into $4 \mu \mathrm{m}$ thick sections. Sections were stained with eosin at room temperature for $10 \mathrm{~min}$ and then stained with hematoxylin for $>15 \mathrm{~min}$ at room temperature according to a previously published protocol (30), and then visualized under a light microscope (magnifications, $\mathrm{x} 100$ and $\mathrm{x} 200$ ).

Statistical analysis. Quantitative data are presented as the mean \pm standard deviation, and statistical analysis was performed using SPSS 20.0 (IBM SPSS, Armonk, NY, USA) and GraphPad Prism 5 software (GraphPad Software, Inc., La Jolla, CA, USA). Significant differences between groups were compared using one-way analysis of variance and Student's t-test. $\mathrm{P}<0.05$ was considered to indicate a statistically significant difference.

\section{Results}

Expression of NEAT1 is high in IBD mice and inflammatory cell lines. To investigate whether abnormal expression levels of NEAT1 were present in IBD, 30 acute and chronic colitis male C57BL/6 mice were induced as a model by feeding $5 \%$ DSS. The expression levels of NEAT1 in the mouse intestinal mucosa and serum were compared between the control and DSS-induced group using RT-qPCR analysis. The mRNA expression of NEAT1 was significantly higher in the colitis mice than in the non-colitis mice in the intestinal mucosa (Fig. 1A) and serum (Fig. 1B).

Exosomes are reported to be important in mediating the immune response though regulation of macrophage activity (26). In the present study, it was hypothesized that the expression of NEAT1 may be dysregulated in exosomes isolated from DSS-induced colitis mouse models. Exosomes were successfully extracted from DSS-induced mouse serum as previously described (31) (Fig. 1C). In addition, the expression levels of NEAT1 were determined in exosomes from DSS-induced colitis mouse serum and normal control mice using RT-qPCR analysis. It was revealed that the expression of NEAT1 was high in serum exosomes from the DSS-induced colitis mice compared with those from the control group (Fig. 1D).

To further support the results that the expression of NEAT1 was high in colitis mouse models, cell experiments were performed to verify these data in inflammatory cell models. The HT-29 and NCM460 cells were induced using $20 \mathrm{ng} / \mathrm{ml}$ of TNF- $\alpha$ for $24 \mathrm{~h}$ to establish the IBD cell models, and the inflammatory cell models were confirmed via RT-qPCR analysis by detecting the inflammatory factors MCP-1 and IL23 (32). The analysis suggested that the relative mRNA expression levels of MCP-1 and IL23 were significantly higher in the TNF- $\alpha$-induced HT-29 ( $\mathrm{P}<0.001$; Fig. 1E) and NCM460 $(\mathrm{P}<0.001$; Fig. 1F) cell lines than in their control group cells. Similarly, RT-qPCR analyses were used to examine the relative expression levels of NEAT1 in HT-29 and NCM460 inflammatory cells, and the data showed that the expression of NEAT1 was high in TNF- $\alpha$-induced HT-29 $(\mathrm{P}<0.001)$ and NCM460 $(\mathrm{P}<0.01)$ cell lines compared with that in the control epithelial cell line (Fig. 1G).

Taken together, the above results showed that the expression of NEAT1 was high in the DSS-induced colitis mice and in the TNF- $\alpha$-induced HT-29 and NCM460 inflammatory cell models, and was hypothesized that the expression levels of NEAT1 may be connected to the occurrence of inflammation.

Knockdown of NEAT1 reverses the TNF- $\alpha$-induced permeability increase in inflammatory HT-29 and NCM460 cells. To examine the regulatory role of NEAT1 in HT-29 and NCM460 cell lines, a lentivirus carrying shRNA-NEAT1 was packaged, and RT-qPCR analysis was used to verify the effectiveness of the lentiviral vector for NEAT1 interference (Fig. 2A). The TEER value is associated with the barrier function and permeability of monolayer cells. In the present study, the TEER value was measured to evaluate the effects of NEAT1 inhibition in TNF- $\alpha$-treated NCM460 and HT-29 cells on monolayer integrity. The TEER value was decreased in the TNF- $\alpha$-treated NCM460 and HT-29 cells; however, the TEER value was increased when the NCM460 and HT-29 cells were treated with TNF- $\alpha$ and LV-shNEAT1 compared with the cells treated with TNF- $\alpha$ only (Fig. 2B).

To further support the above results, permeability assays were preformed to examine the change in the barrier property following TNF- $\alpha$ induction and the downregulation of NEAT1 in NCM460 and HT-29 monolayers by detecting the FITC-dextran concentration; the percentage of apical FITC-dextran was negatively correlated with the cell barrier property. The results of the permeability assays showed that the percentage of apical FITC-dextran was increased in the TNF- $\alpha$-induced NCM460 and HT-29 cells compared with that in the control cells, and the ratio was decreased when the NCM460 and HT-29 cells were treated with TNF- $\alpha$ and LV-shNEAT1 (Fig. 2C).

According to the TEER and permeability assay results, in the inflammatory cells (cells treated with TNF- $\alpha$ ), NEAT1 was associated with the barrier property, which is determined by junction complexes among cells that provide a physical and biochemical barrier to regulate the passage of ions and small molecules. The ZO-1, Claudin-5 and Occludin proteins were detected by western blot analysis and were found to be expressed at high levels in the NEAT1-inhibited NCM460 and HT-29 cells, and only marginally expressed in TNF- $\alpha$-induced inflammatory cells compared with the negative control cells. Similarly, the connexins ZO-1, Claudin-5 and Occludin were expressed at higher levels in the NEAT1-inhibited inflam- 
A

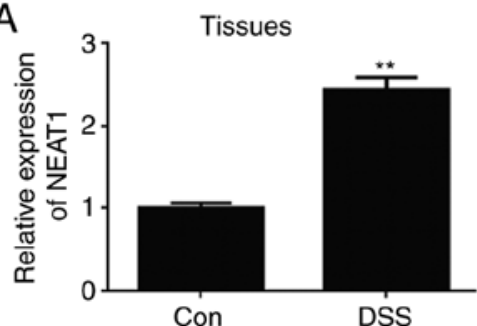

B

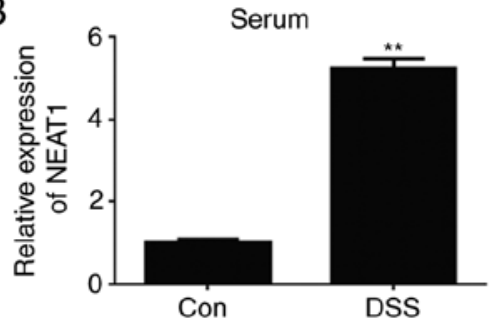

C
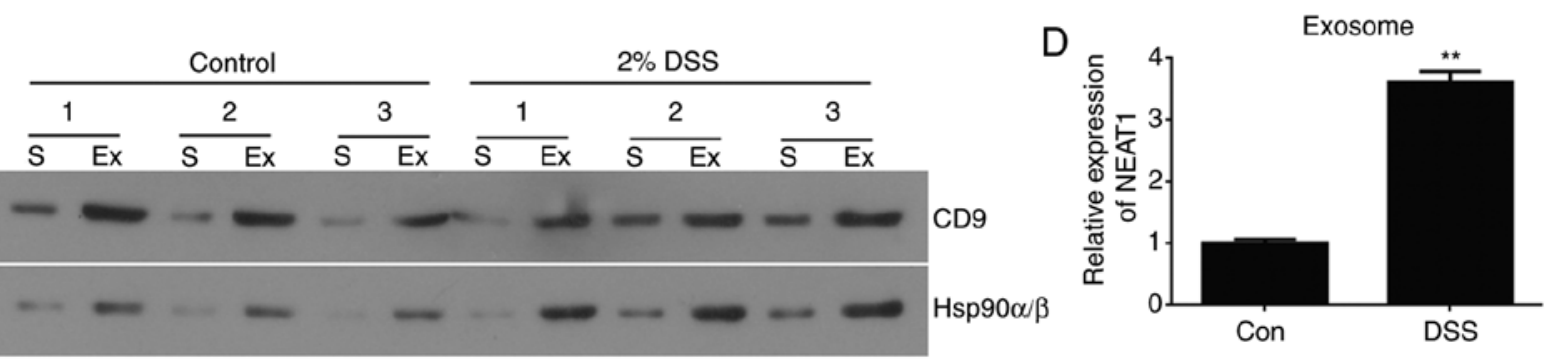

$\mathrm{E}$

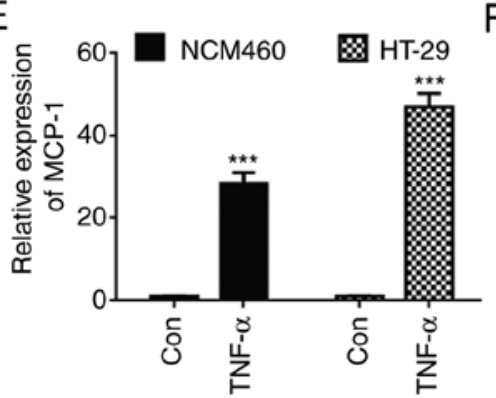

$\mathrm{F}$
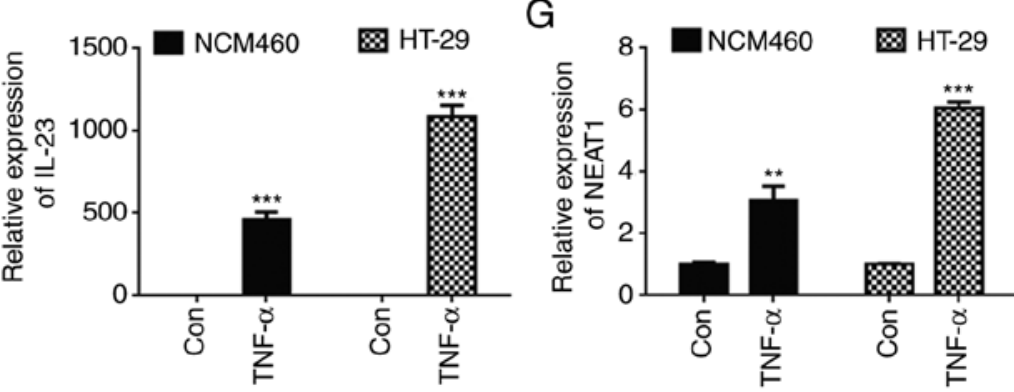

Figure 1. Expression of NEAT1 is high in an inflammatory bowel disease mouse model and inflammatory cell line models. Relative expression levels of NEAT1 were compared in (A) intestinal mucosa tissue and (B) serum from DSS-induced colitis mice between normal control mice using RT-qPCR analysis. (C) Western blot analyses of Hsp90 $\alpha / \beta$ and CD9 protein expression in exosome-rich fractions and serum. (D) Quantification of western blot results (E) RT-qPCR analyses of mRNA expression of NEAT1 in exosomes from DSS-induced colitis mice and normal control mice. The relative expression of inflammatory factors (E) MCP-1 and (F) IL23 was detected in HT-29 and NCM460 TNF- $\alpha$-induced inflammatory cell lines using RT-qPCR analysis. (G) RT-qPCR analyses of the relative mRNA expression of NEAT1 in TNF- $\alpha$-induced HT-29 and NCM460 inflammatory cell lines. The data are shown as the mean \pm standard deviation; ${ }^{* *} \mathrm{P}<0.01$ and ${ }^{* * *} \mathrm{P}<0.001$. NEAT1, Nuclear paraspeckle assembly transcript 1 ; Con, control; DSS, dextran sulfate sodium; RT-qPCR, reverse transcription-quantitative polymerase chain reaction; Ex, exosome-rich fraction; $\mathrm{S}$, serum; TNF- $\alpha$, tumor necrosis factor- $\alpha$; ZO-1, Zonula occludens-1; MCP-1, Monocyte chemoattractant protein 1; IL-23, Interleukin-23.

matory NCM460 and HT-29 cells than in the inflammatory NCM460 and HT-29 cells (Fig. 2D). Similar results were obtained in the immunofluorescence assays used to detect the protein expression of Occludin, which is an integral transmembrane protein that has been confirmed to have important functions in the regulation of the paracellular permeability of epithelial monolayers (33) (Fig. 2E).

Taken together, these data suggested that TNF- $\alpha$ mediated the permeability increase in NCM460 and HT-29 cells; however, NEAT1 inhibition had an adverse function and reversed the TNF- $\alpha$-induced increase in the permeability of inflammatory cells.

Knockdown of NEAT1 suppresses the DSS-induced permeability increase in colon tissues from IBD mice. For an improved understanding of the biology and regulatory functions of NEAT1 in IBDs in vivo, further experiments in IBD mouse models induced by $5 \%$ DSS were performed. The results of H\&E staining (Fig. 3A) suggested that the intestinal epithelial tissues were damaged in the DSS-induced IBD mice, whereas the intestinal epithelial tissues of the DSS-induced IBD mice treated with LV-shNEAT1 were less damaged, compared with those in the group of DSS-induced IBD mice. Furthermore, the DSS-induced IBD mice had a lower body weight than the control healthy mice, and the NEAT1-inhibited IBD mice had significantly higher body weights compared with the IBD mice; similar results were acquired on measuring colon length (Fig. 3B and C). The relative expression of NEAT1 was detected in the colon tissue of IBD mice using RT-qPCR analysis, and the results suggested that the expression of NEAT1 was high in the DSS-induced colon tissue, and when the IBD mice were treated with LV-shNEAT1, the relative expression of NEAT1 was reduced compared with that in the IBD mice (Fig. 4A).

To detect whether NEAT1 is associated with the permeability of colon tissue in vivo, western blot analysis (Fig. 4B-D) and immunohistochemical experiments (Fig. 4E) were performed to detect the expression of connexins, including ZO-1 and Occludin. The results showed that the expression levels of ZO-1 and Occludin was decreased in the DSS-induced mouse colon tissue compared with those in the negative control mice, and when the IBD mice were treated with LV-shNEAT1, the expression levels of ZO-1 and Occludin was increased compared with those in the DSS-induced IBD mice. Furthermore, permeability assays were performed to examine 

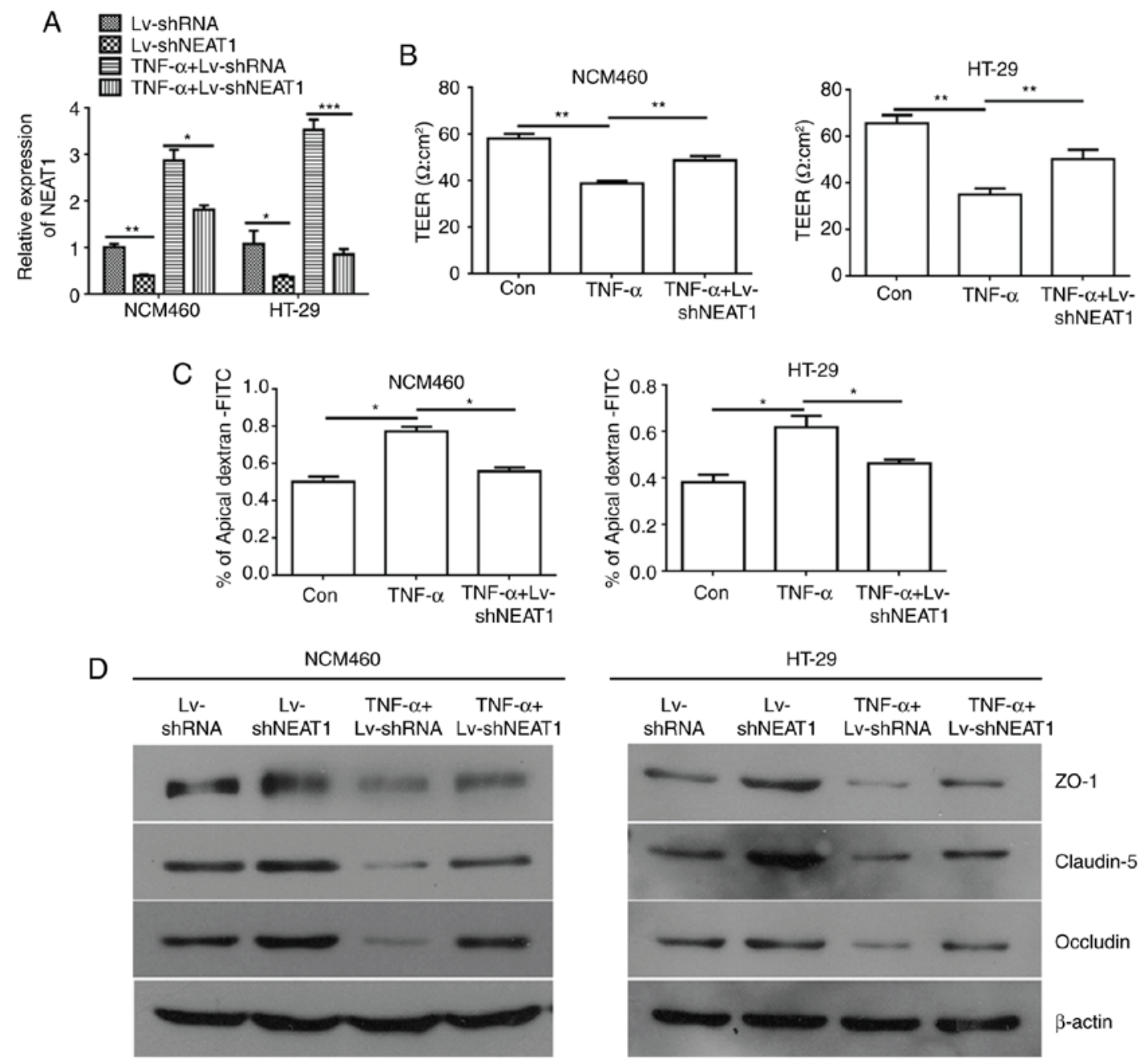

$\mathrm{E}$
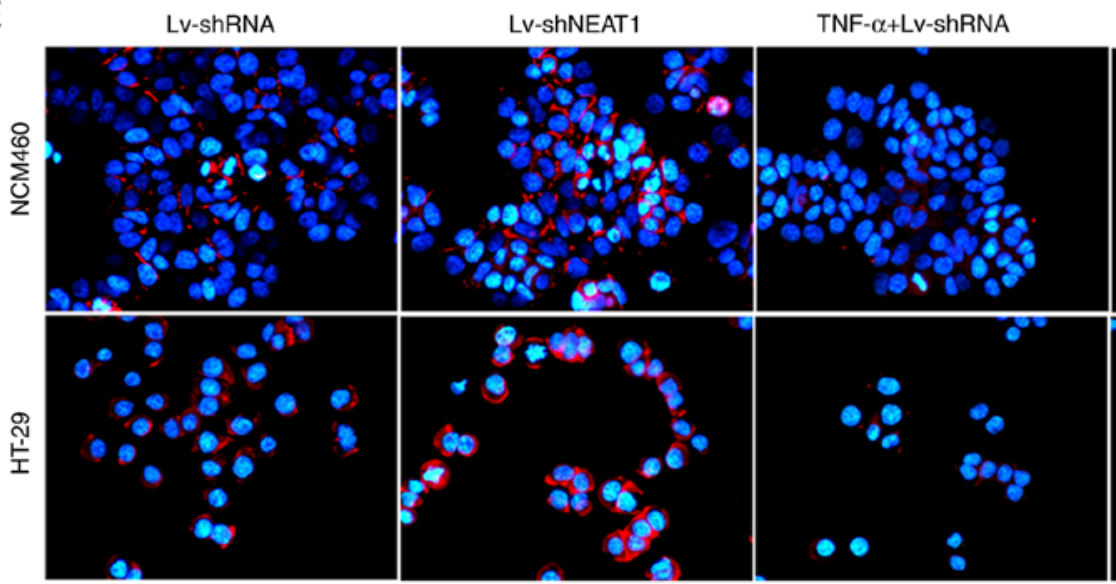

TNF- $\alpha+L v-$ ShNEAT1

Figure 2. NEAT1 inhibition reverses the TNF- $\alpha$-induced permeability increase in inflammatory HT-29 and NCM460 cells. (A) Relative expression of NEAT1 was detected in NCM460 and HT-29 cells treated with LV-shNEAT1 and TNF- $\alpha$ using RT-qPCR analysis. (B) TEER values were monitored in NCM460 and HT-29 cells treated with LV-shNEAT1 and TNF- $\alpha$. (C) Permeability assays were performed to detect the barrier state in NCM460 and HT-29 cells. (D) Western blot analysis was used to detect the expression of ZO-1, Claudin-5 and Occludin. (E) Immunofluorescence analyses of the protein expression of Occludin in NCM460 and HT-29 cells (magnification, $\mathrm{x} 400$ ). ${ }^{*} \mathrm{P}<0.05,{ }^{* * *} \mathrm{P}<0.01$ and ${ }^{* * * *} \mathrm{P}<0.001$. NEAT1, nuclear paraspeckle assembly transcript 1; shRNA, short hairpin RNA; Con, control; TEER, trans-epithelial electrical resistance; TNF- $\alpha$, tumor necrosis factor- $\alpha$; ZO-1, zonula occludens-1; RT-qPCR, reverse transcription-quantitative polymerase chain reaction; FITC, fluorescein isothiocyanate.

changes in the barrier property of intestinal epithelial tissues from mouse models (Fig. 4F). The data indicated that the FITC-dextran concentration, representing colon permeability, was significantly increased in colon tissues from DSS-induced mice, compared with the negative control group, whereas the permeability decreased in the DSS-induced IBD mice treated with LV-shNEAT1 compared with the DSS-induced IBD mice, and these results demonstrated that the inhibition of NEAT1 suppressed the permeability increase in colon tissues from DSS-induced IBD mice. 

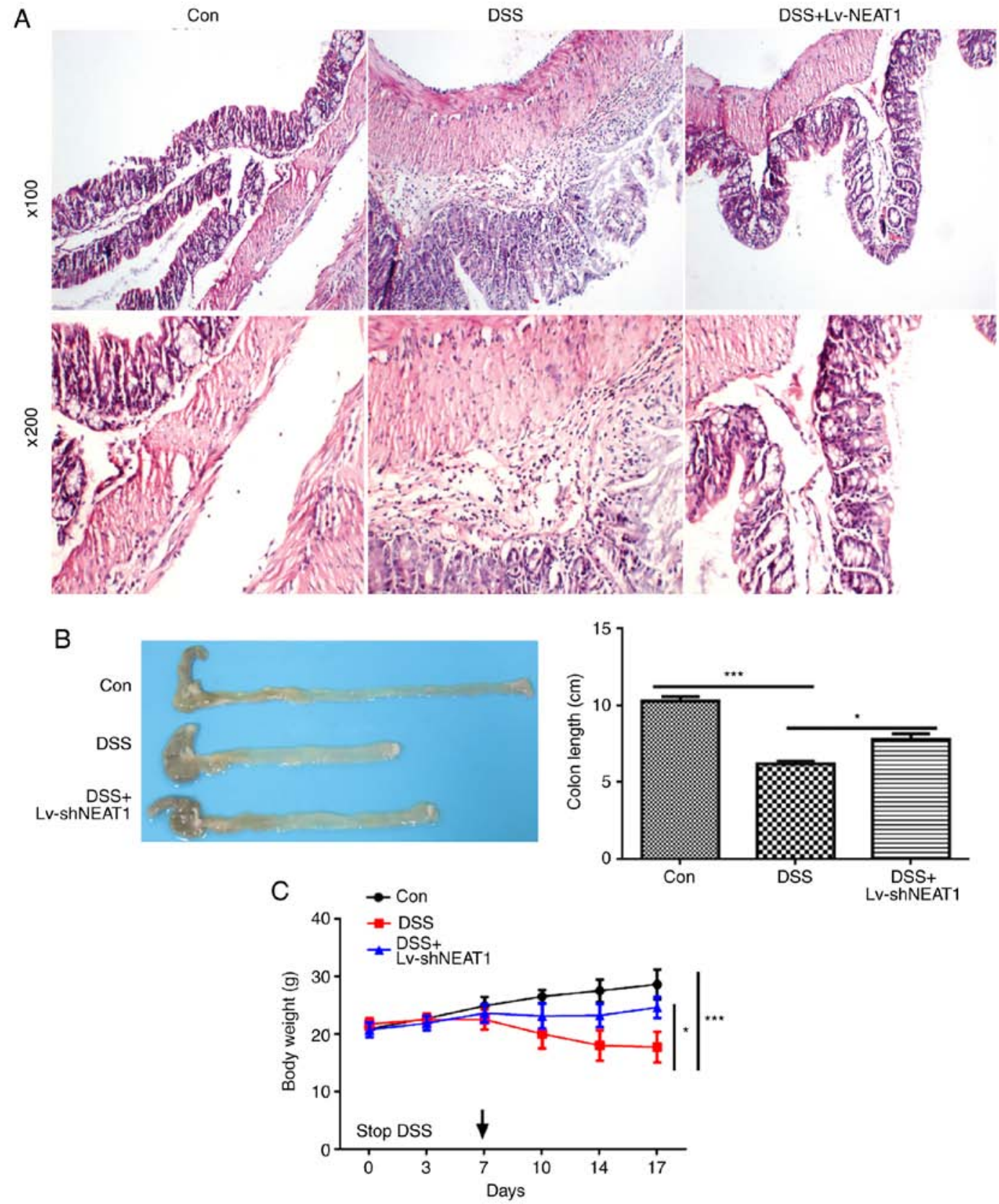

Figure 3. Knockdown of NEAT1 suppresses DSS-induced inflammatory bowel disease in mice. (A) Intestinal epithelial tissues of mice were observed following hematoxylin and eosin staining. (B) Colon length and (C) body weights of mice were measured to assess the effects of DSS and long non-coding RNA NEAT1. "P<0.05 and ${ }^{* * *} \mathrm{P}<0.001$. NEAT1, Nuclear paraspeckle assembly transcript 1; Con, control; DSS, dextran sulfate sodium; shNEAT1, short hairpin RNA targeting NEAT1.

Together, these results showed that DSS induced a permeability increase in colon tissues, and NEAT1 inhibition reversed the effect of DSS and decreased the permeability of colon tissues from IBD mice.

NEATl inhibition suppresses the inflammatory reaction and may be associated with the function of exosomes. An improved understanding of the regulatory functions of NEAT1 in IBDs is important for developing novel strategies for IBD therapy by targeting NEAT1. The previous section examined whether NEAT1 was associated with inflammation occurrence, and NEAT1 inhibition was found to suppress the TNF- $\alpha$-induced increase in epithelial cell permeability. Additional experiments were preformed to understand the molecular mechanism of
NEAT1 in the inflammatory response. In this experiment, the RAW246.7 macrophage cell line was treated with exosomes purified from DSS-induced or control male C57BL/6(B6) mouse blood serum, and the protein expression of classically activated (M1) macrophage markers, including IL23 and iNOS, and alternatively activated (M2) macrophage markers, including IL10, CD206 and Arg-1, were determined using western blot assays. The results showed that the expression levels of IL23 and iNOS were high in RAW246.7 cells treated with DSS-induced serum exosomes. By contrast, the M2 macrophage markers IL10, CD206 and Arg-1 were only marginally expressed in RAW246.7 cells treated with DSS-induced serum exosomes compared with the negative control exosome-treated group (Fig. 5A). The data suggested 

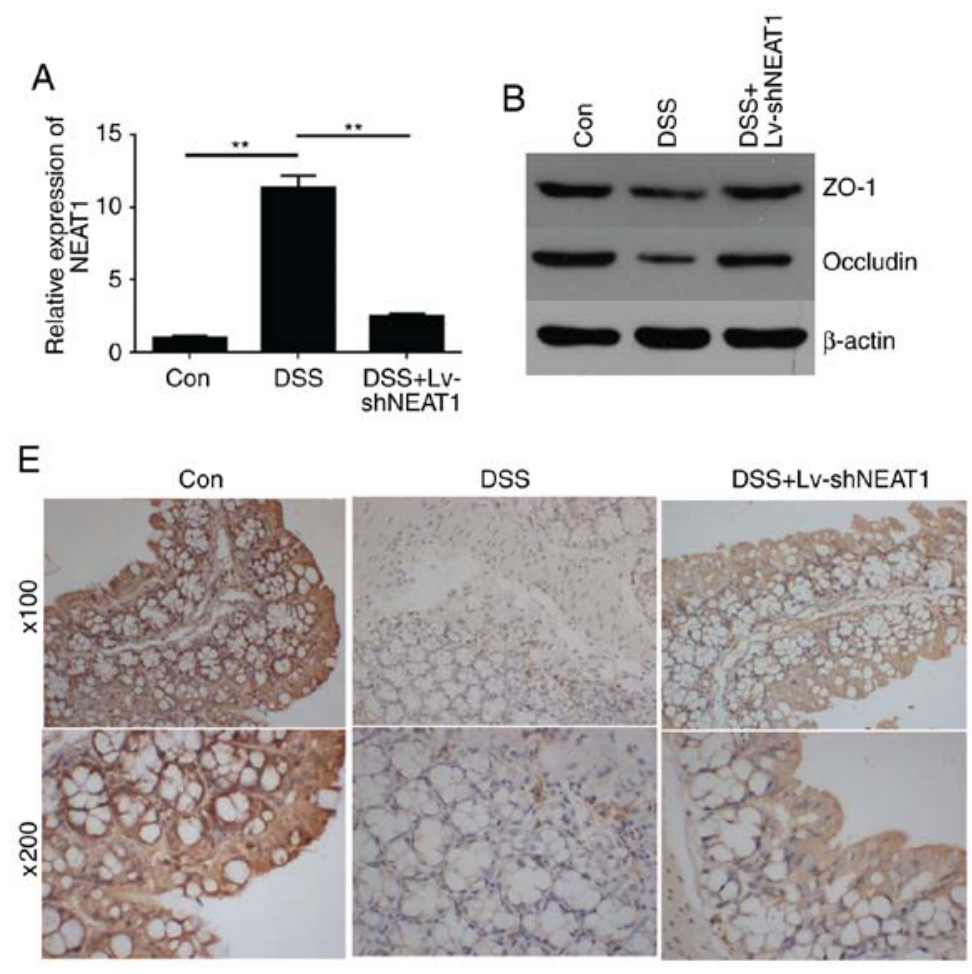
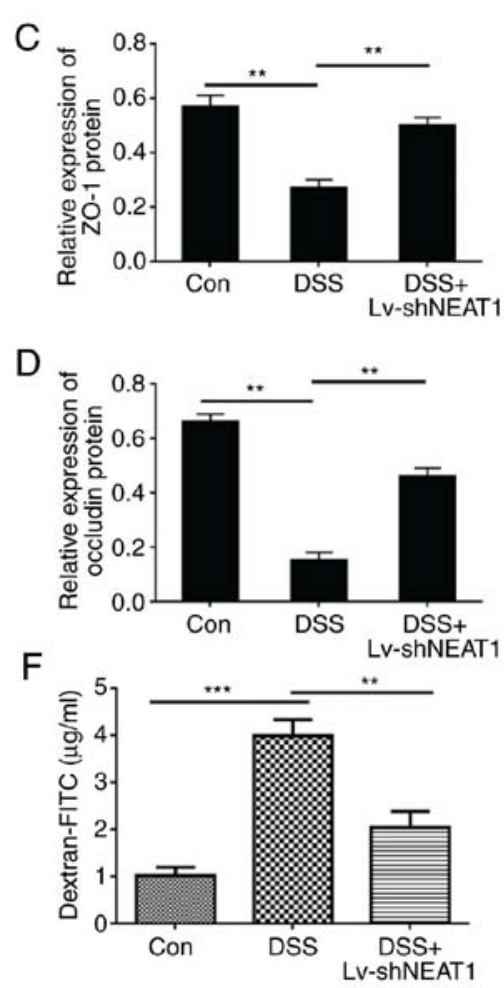

Figure 4. Knockdown of NEAT1 suppresses the DSS-induced permeability increase in colon tissues from IBD mice. (A) Relative expression of NEAT1 was detected in colon tissue from DSS-induced IBD mice using reverse transcription-quantitative polymerase chain reaction analysis. (B) Western blot analysis was used to detect the protein expression of (C) ZO-1 and (D) Occludin. (E) Immunohistochemical experiments were performed to detect the protein expression of Occludin in mouse colon tissues. (F) Permeability of colon tissues was examined by detecting the FITC-dextran concentration in the IBD mouse model. ${ }^{* *} \mathrm{P}<0.01$ and ${ }^{* * *} \mathrm{P}<0.001$. IBD, inflammatory bowel disease; NEAT1, Nuclear paraspeckle assembly transcript 1; Con, control; DSS, dextran sulfate sodium; shNEAT1, short hairpin RNA targeting NEAT1; ZO-1, Zonula occludens-1.

that DSS induced macrophage activation and activated the inflammatory response.

To further detect the function of NEAT1 in the inflammatory response, the cell supernatants of LV-shNEAT1-treated and TNF- $\alpha$-induced inflammatory NCM460 and HT-29 cells were obtained, and western blot analysis was performed to examine the protein expression levels of the macrophage markers IL23, iNOS, IL10, CD206 and Arg-1. The results suggested that the expression levels of M1 macrophage markers IL23 and iNOS were high and those of the M2 macrophage markers IL10, CD206 and Arg-1 were low in the TNF- $\alpha$-induced NCM460 and HT-29 cells compared with the negative control group (Fig. 5B). Compared with the TNF- $\alpha$-induced NCM460 and HT-29 cells, the expression of levels M1 macrophage markers IL23 and iNOS were decreased and the expression levels of the M2 macrophage markers IL10, CD206 and Arg-1 were increased when NCM460 and HT-29 cells were treated with TNF- $\alpha$ and LV-shNEAT1 (Fig. 5B). Together, these data showed that TNF- $\alpha$ promoted macrophage transformation to M1 and activated the inflammatory response, whereas NEAT1 inhibition promoted macrophage transformation to $\mathrm{M} 2$ and suppressed the inflammatory response in TNF- $\alpha$-induced NCM460 and HT-29 cells. The protein expression of iNOS and CD206 was verified by flow cytometry, and the results suggested that the expression of CD206 was increased and the expression of iNOS was decreased in the TNF- $\alpha$-induced epithelial cells, and the opposite results were obtained when TNF- $\alpha$-induced epithelial cells were treated with LV-shNEAT1 (Fig. 5C).
Taken together, these data supported the hypothesis that NEAT1 inhibition promotes macrophage M1 transformation to M2 and suppresses the inflammatory reaction. These communication processes between epithelial cells and macrophages may be dependent on the effect of exosomes.

\section{Discussion}

There is increasing evidence that lncRNAs are critical in immune system regulation, and numerous IncRNAs have been found to be deregulated in IBD (5). In addition, increasing evidence supports the hypothesis that NEAT1 is associated with the immune response in various ways $(34,35)$. A report by Imamura et al (16) demonstrated that NEAT1 is important in the innate immune response by facilitating the expression of antiviral genes, including the cytokine IL8. However, the effect of NEAT1 in IBD has not been determined previously. Therefore, the present study investigated the function of NEAT1 in IBD. It was found that the expression of NEAT1 was high in DSS-induced mouse intestinal tissues, serum and exosomes, and was also high in TNF- $\alpha$-induced HT-29 and NCM460 inflammatory cell models compared with control group cells. These results suggested that the expression of NEAT1 is high in IBD, and the data revealed that NEAT1 may be important in regulation of the inflammatory response in IBD. The present study revealed the possible benefits of examining the mechanisms underlying the pathogenesis of IBD, suggest the future use of NEAT1 as a biomarker for the diagnosis and treatment of IBD. 


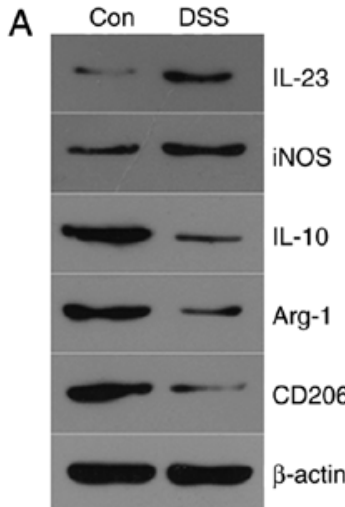

B

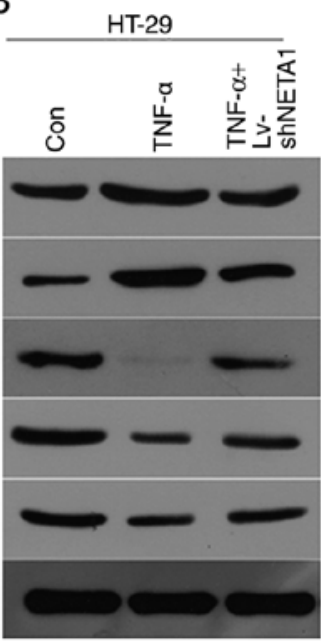

206
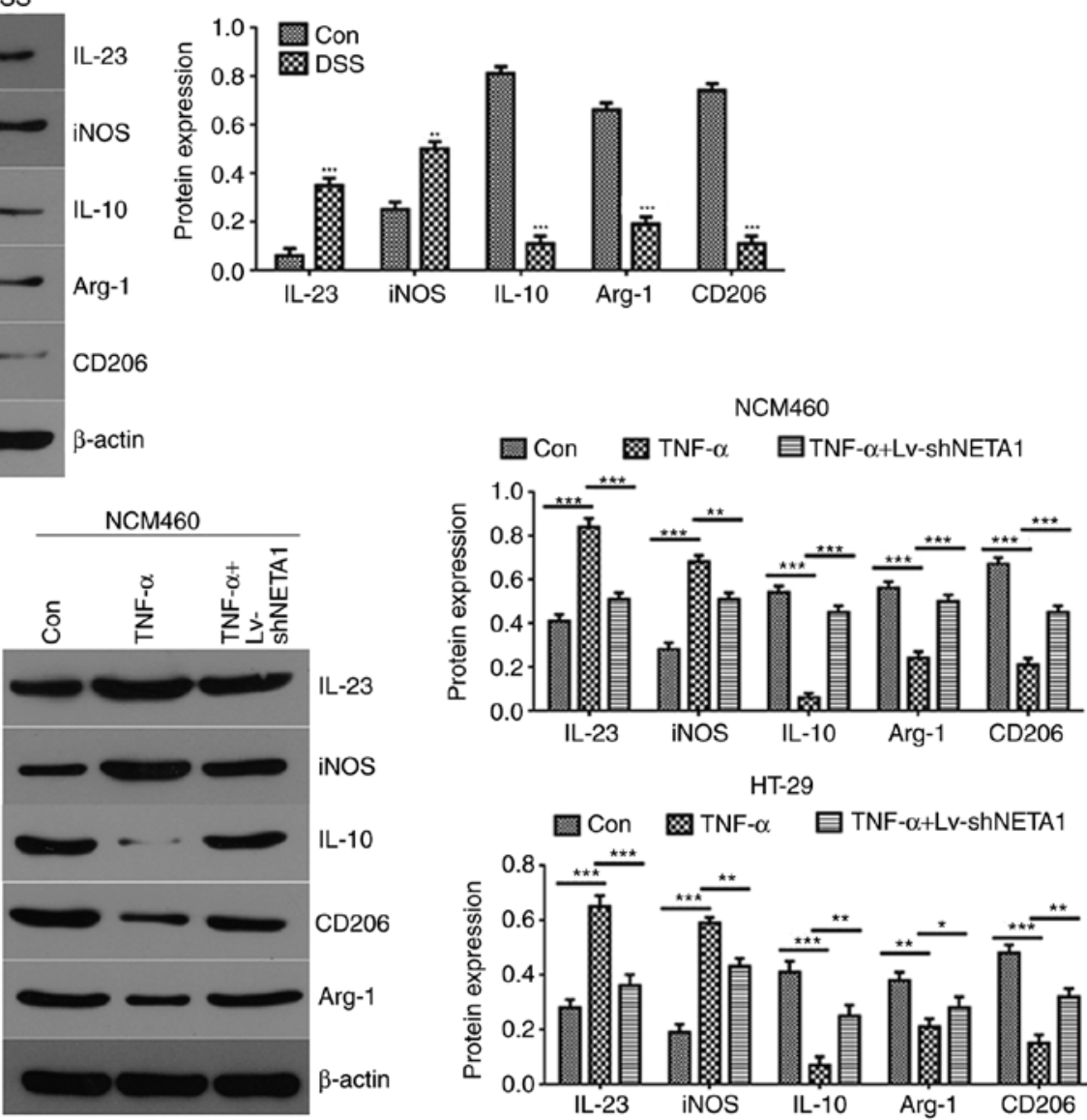

HT-29

$\square$ Con $\otimes T N F-\alpha$ 目TNF- $\alpha+$ Lv-shNETA1

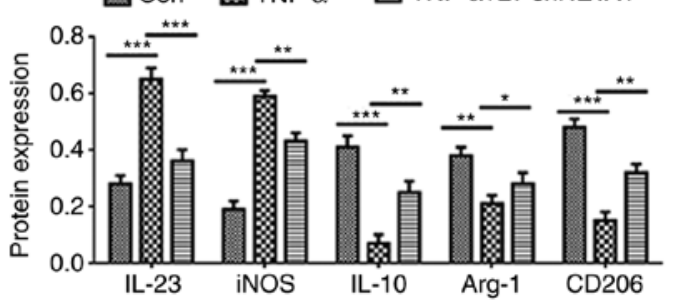

C
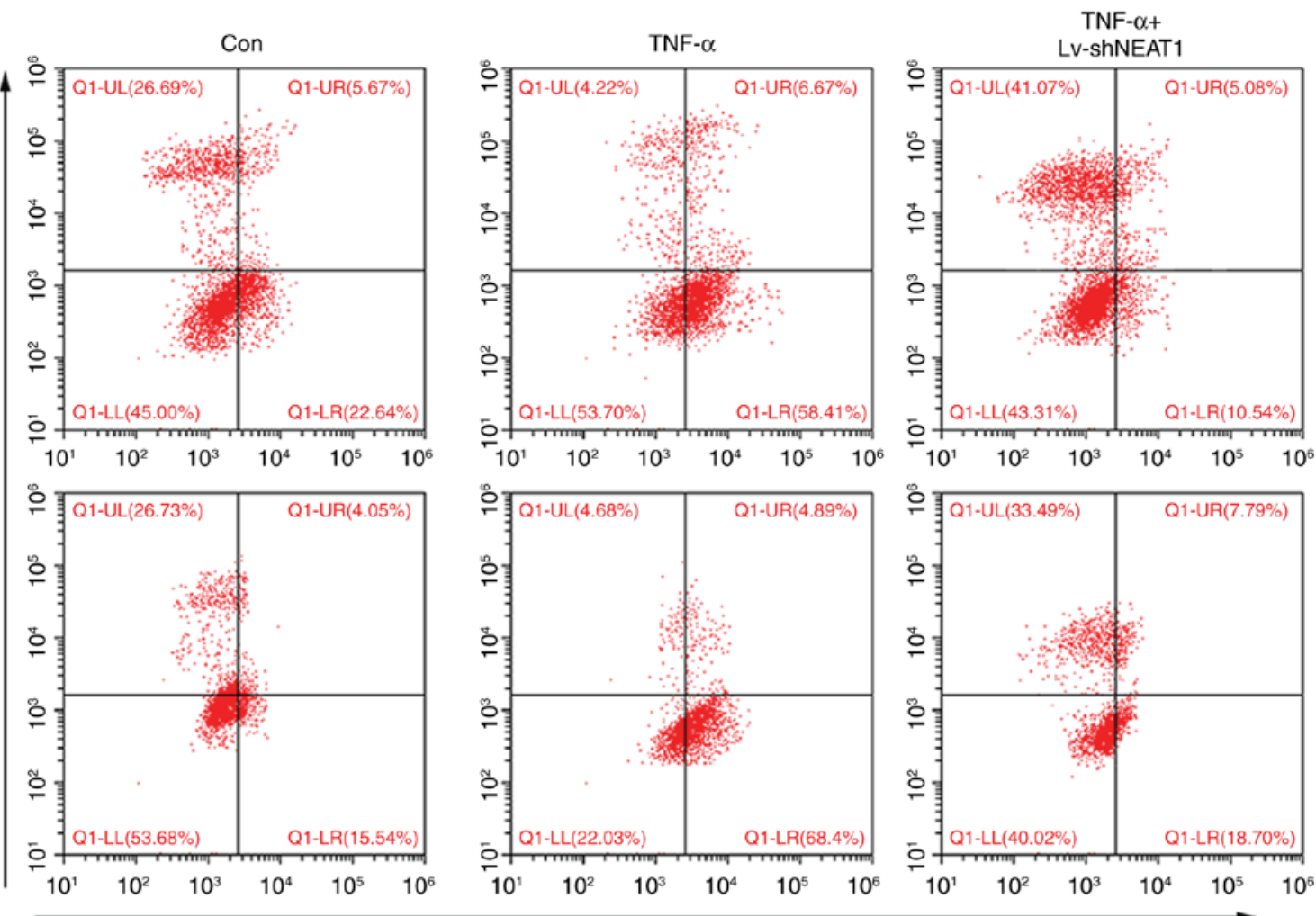

iNOS

Figure 5. NEAT1 inhibition suppresses the inflammatory reaction, which may be associated with the function of exosomes. (A) Western blot analysis was used to detect the expression of IL23, iNOS, IL10, CD206 and Arg-1 in RAW246.7 cells treated with DSS-induced serum exosomes. (B) Expression of IL23, iNOS, IL10, CD206 and Arg-1 was detected by western blot analysis following NEAT1 inhibition in TNF- $\alpha$-induced NCM460 and HT-29 cells. (C) Flow cytometric analyses of the expression of iNOS and CD206 in TNF- $\alpha$-induced NEAT1-inhibited epithelial cells. ${ }^{*} \mathrm{P}<0.05,{ }^{* *} \mathrm{P}<0.01$ and ${ }^{* * *} \mathrm{P}<0.001$. NEAT1, Nuclear paraspeckle assembly transcript 1; Con, control; DSS, dextran sulfate sodium; shNEAT1, short hairpin RNA targeting NEAT1; TNF- $\alpha$, tumor necrosis factor- $\alpha$; IL, Interleukin; iNOS, Inducible nitric oxide synthase; Arg-1, Arginase-1. 
The intestinal barrier, which acts as the mammalian host defense against the external microenvironment and exhibits selective permeability for the absorption of nutrients, is attracting increased attention as a critical factor in the occurrence of IBD (36). In addition, the intestinal barrier is covered by a cell monolayer composed of different intestinal epithelial cell subtypes that maintains intestinal homeostasis by controlling the crosstalk between microbiota and subjacent immune cells (37). The epithelial monolayer acts as a protective physical barrier and is mediated by the formation of a web of tight junctions, which regulate paracellular permeability and barrier integrity (38). Dysfunction of the intestinal epithelial barrier is mainly caused by epithelial cell apoptosis and the loss of function of tight junctions, increasing the chances of microorganism invasion through intestinal mucous membranes. Consistently, dysfunction of the intestinal epithelial barrier is associated with the pathogenesis of IBD $(39,40)$. Therefore, further investigations to expand current knowledge of the intestinal epithelial barrier are important for IBD treatment. NEAT1 was found to be expressed at high levels in inflammatory cells in the present study, and it was hypothesized that it may influence the integrity and permeability of the intestinal epithelial barrier in IBD. In TNF- $\alpha$-induced HT-29 and NCM460 cells, it was found that cell permeability was increased compared with that in control group cells; however, when the expression of NEAT1 in was inhibited in TNF- $\alpha$-induced HT-29 and NCM460 inflammatory cells, the permeability decreased compared with that in the TNF- $\alpha$-induced cells. Similar results were obtained in the DSS-induced IBD mouse models. Together, these results suggested that permeability was increased in the TNF- $\alpha$ - and DSS-induced IBD models, and that the inhibition of NEAT1 reversed the effect of TNF- $\alpha$ and DSS and reduced the permeability of epithelial cells. These data indicated that TNF- $\alpha$ and DSS disrupted the integrity of the intestinal epithelial barrier and finally led to the occurrence of IBD, whereas the inhibition of NEAT1 enhanced intestinal epithelial barrier integrity.

NEAT1 has been verified to be involved in the inflammatory response by regulating the intestinal epithelial barrier in IBD. In the inflammatory process, inflammatory cytokines secreted by epithelial cells trigger the immune response. Furthermore, $\mathrm{T}$ cell and macrophage recruitment to the region of intestinal tissue injury is another way to defend against a harmful microenvironment $(41,42)$. However, whether NEAT1 influences the function of macrophages remains to be fully elucidated. In the present study, a DSS-induced acute colitis mouse model was used to investigate the effect of serum exosomes, which contain high levels of 1ncRNANEAT1, on TNF- $\alpha$-induced macrophages. RAW246.7 macrophages were treated with serum exosomes isolated from DSS-induced mice. It was found that the expression levels of M1 macrophage markers were high and those of M2 macrophage marker expression were low compared with levels in cells treated with exosomes isolated from control mice. The results suggested that DSS induced M1 macrophage activation. In the TNF- $\alpha$-induced inflammatory NCM460 and HT-29 cells, similar results were obtained, suggesting that TNF- $\alpha$ induced M1 macrophage activation. However, when the expression of NEAT1 was inhibited in TNF- $\alpha$-induced cells, M1 macrophage activation was suppressed. The present study revealed for the first time, to the best of our knowledge, that NEAT1 in exosomes affects the phenotype transformation between epithelial cells and macrophages.

In conclusion, the present study demonstrated that the expression of NEAT1 was high in IBD and was involved in the inflammatory response by regulating the intestinal epithelial barrier and exosome-mediated polarization of macrophages in IBD. Further knowledge of the role of NEAT1 in IBD contributes to an improved understanding of the pathogenesis of IBD and provides further insight into the potential and efficacy of NEAT1-based prevention and treatment options.

\section{Acknowledgements}

The authors would like to thank the reviewers for their helpful comments on this manuscript.

\section{Funding}

The study was supported by the Foundation of Hunan Provincial Science and Technology Department, China (grant no. 2016JC2051).

\section{Availability of data and materials}

The data used and/or analyzed during the present study are available from the corresponding author on reasonable request.

\section{Authors' contributions}

RL designed the study, collected data, interpreted data and prepared manuscript, and was a major contributor in writing the manuscript. SS designed the study, interpreted data, performed literature search and obtained funding. AT and XC performed statistical analysis. XW collected data. LZ prepared the manuscript. ZX interpreted data. All authors have read and approved the final manuscript.

\section{Ethics approval and consent to participate}

All procedures performed in the present study involving human participants were in accordance with the ethical standards of the Ethical Meeting of Biomedical Research, The Third Xiangya Hospital of Central South University.

\section{Patient consent for publication}

Not applicable.

\section{Competing interests}

The authors declare that they have no competing interests.

\section{References}

1. Sairenji T, Collins KL and Evans DV: An update on inflammatory bowel disease. Prim Care 44: 673-692, 2017.

2. Antoni L, Nuding S, Wehkamp J and Stange EF: Intestinal barrier in inflammatory bowel disease. World J Gastroenterol 20: 1165-1179, 2014.

3. Jäger S, Stange EF and Wehkamp J: Inflammatory bowel disease: An impaired barrier disease. Langenbecks Arch Surg 398: 1-12, 2013. 
4. Guttman M, Amit I, Garber M, French C, Lin MF, Feldser D, Huarte M, Zuk O, Carey BW, Cassady JP, et al: Chromatin signature reveals over a thousand highly conserved large non-coding RNAs in mammals. Nature 458: 223-227, 2009.

5. Zacharopoulou E, Gazouli M, Tzouvala M, Vezakis A and Karamanolis G: The contribution of long non-coding RNAs in inflammatory bowel diseases. Dig Liver Dis 49: 1067-1072, 2017.

6. Chen SW, Wang PY, Liu YC, Sun L, Zhu J, Zuo S, Ma J, Li TY, Zhang JL, Chen GW, et al: Effect of long noncoding RNA H19 overexpression on intestinal barrier function and its potential role in the pathogenesis of ulcerative colitis. Inflamm Bowel Dis 22: 2582-2592, 2016.

7. Choudhry H, Albukhari A, Morotti M, Haider S, Moralli D, Smythies J, Schödel J, Green CM, Camps C, Buffa F, et al: Tumor hypoxia induces nuclear paraspeckle formation through HIF-2 $\alpha$ dependent transcriptional activation of NEAT1 leading to cancer cell survival. Oncogene 34: 4546, 2015.

8. Clemson CM, Hutchinson JN, Sara SA, Ensminger AW, Fox AH Chess A and Lawrence JB: An architectural role for a nuclear noncoding RNA: NEAT1 RNA is essential for the structure of paraspeckles. Mol Cell 33: 717-726, 2009.

9. Nakagawa S, Shimada M, Yanaka K, Mito M, Arai T, Takahashi E, Fujita Y, Fujimori T, Standaert L, Marine JC and Hirose T: The lncRNA Neat1 is required for corpus luteum formation and the establishment of pregnancy in a subpopulation of mice. Development 141: 4618-4627, 2014.

10. Lin D: Commentary on 'The oestrogen receptor alpha-regulated lncRNA NEAT1 is a critical modulator of prostate cancer.' Chakravarty D, Sboner A, Nair SS, Giannopoulou E, Li R, Hennig S, Mosquera JM, Pauwels J, Park K, Kossai M, MacDonald TY, Fontugne J, Erho N, Vergara IA, Ghadessi M, Davicioni E, Jenkins RB, Palanisamy N, Chen Z, Nakagawa S, Hirose T, Bander NH, Beltran H, Fox AH, Elemento O, Rubin MA, University of Washington-Urology, Seattle, WA. Nat Commun 2014; 5: 5383. Urol Oncol 34: 522, 2016.

11. Chakravarty D, Sboner A, Nair SS, Giannopoulou E, Li R, Hennig S, Mosquera JM, Pauwels J, Park K, Kossai M, et al: The oestrogen receptor alpha-regulated lncRNA NEAT1 is a critical modulator of prostate cancer. Nat Commun 5: 5383, 2014.

12. Zeng C, Xu Y, Xu L, Yu X, Cheng J, Yang L, Chen S and Li Y: Inhibition of long non-coding RNA NEAT1 impairs myeloid differentiation in acute promyelocytic leukemia cells. Bmc Cancer 14: 693, 2014

13. Peng W, Wang $Z$ and Fan H: LncRNA NEAT1 impacts cell proliferation and apoptosis of colorectal cancer via regulation of Akt signaling. Pathol Oncol Res 23: 651-656, 2017.

14. Li Y, Li Y, Chen W, He F, Tan Z, Zheng J, Wang W, Zhao Q and Li J: NEAT expression is associated with tumor recurrence and unfavorable prognosis in colorectal cancer. Oncotarget 6 : 27641-27650, 2015.

15. Morchikh M, Cribier A, Raffel R, Amraoui S, Cau J, Severac D, Dubois E, Schwartz O, Bennasser Y and Benkirane M: HEXIM1 and NEAT1 long non-coding RNA form a multi-subunit complex that regulates DNA-mediated innate immune response. Mol Cell 67: 387-399.e5, 2017.

16. ImamuraK, ImamachiN,Akizuki G,Kumakura M,Kawaguchi A Nagata K, Kato A, Kawaguchi Y, Sato H, Yoneda M, et al: Long noncoding RNA NEAT1-dependent SFPQ relocation from promoter region to paraspeckle mediates IL8 expression upon immune stimuli. Mol Cell 53: 393-406, 2014.

17. Guo J, Cai H, Zheng J, Liu X, Liu Y, Ma J, Que Z, Gong W, Gao Y, Tao W and Xue Y: Long non-coding RNA NEAT1 regulates permeability of the blood-tumor barrier via miR-181d-5p-mediated expression changes in ZO-1, occludin, and claudin-5. Biochim Biophys Acta 1863: 2240-2254, 2017

18. Zhang F, Wu L, Qian J, Qu B, Xia S, La T, Wu Y, Ma J, Zeng J, Guo Q, et al: Identification of the long noncoding RNA NEAT1 as a novel inflammatory regulator acting through MAPK pathway in human lupus. J Autoimmun 75: 96-104, 2016.

19. Jiang X, Zhou Y, Sun AJ and Xue JL: NEAT1 contributes to breast cancer progression through modulating miR-448 and ZEB1. J Cell Physiol 2018.

20. Xiong W, Huang C, Deng H, Jian C, Zen C, Ye K, Zhong Z, Zhao X and Zhu L: Oncogenic non-coding RNA NEAT1 promotes the prostate cancer cell growth through the SRC3/IGF1R/AKT pathway. Int J Biochem Cell Biol 94: 125-132, 2018.

21. Li W, Zhang Z, Liu X, Cheng X, Zhang Y, Han X, Zhang Y, Liu S, Yang J, Xu B, et al: The FOXN3-NEAT1-SIN3A repressor complex promotes progression of hormonally responsive breast cancer. J Clin Invest 127: 3421-3440, 2017.
22. Cosenza S, Ruiz M, Maumus M, Jorgensen C and Noël D: Pathogenic or therapeutic extracellular vesicles in rheumatic diseases: Role of mesenchymal stem cell-derived vesicles. Int J Mol Sci 18: E889, 2017.

23. Maas SLN, Breakefield XO and Weaver AM: Extracellular vesicles: Unique intercellular delivery vehicles. Trends Cell Biol 27: 172-188, 2017.

24. Colombo M, Raposo G and Théry C: Biogenesis, secretion, and intercellular interactions of exosomes and other extracellular vesicles. Annu Rev Cell Dev Biol 30: 255-289, 2014

25. Xu AT, Lu JT, Ran ZH and Zheng Q: Exosome in intestinal mucosal immunity. J Gastroenterol Hepatol 31: 1694-1699, 2016.

26. Wong WY, Lee MM, Chan BD, Kam RK, Zhang G, Lu AP and Tai WC: Proteomic profiling of dextran sulfate sodium induced acute ulcerative colitis mice serum exosomes and their immunomodulatory impact on macrophages. Proteomics 16: 1131-1145, 2016.

27. Livak KJ and Schmittgen TD: Analysis of relative gene expression data using real-time quantitative PCR and the 2(-Delta Delta C(T)) method. Methods 25: 402-408, 2001

28. Espiña B, Otero P, Louzao MC, Alfonso A and Botana LM: 13-Desmethyl spirolide-c and 13,19-didesmethyl spirolide-c trans-epithelial permeabilities: Human intestinal permeability modelling. Toxicology 287: 69-75, 2011.

29. Ren DY, Li C, Qin YQ, Yin RL, Du SW, Ye F, Liu HF, Wang MP, Sun Y,Li X, et al: Lactobacilli reduce chemokine IL-8 production in response to TNF-alpha and Salmonella challenge of Caco-2 cells. Biomed Res Int 2013: 925219, 2013.

30. Yin J, Wu M, Duan J, Liu G, Cui Z, Zheng J, Chen S, Ren W, Deng J, Tan X, et al: Pyrrolidine dithiocarbamate inhibits NF-KappaB activation and upregulates the expression of Gpx1, Gpx4, occludin, and ZO-1 in DSS-induced colitis. Appl Biochem Biotechnol 177: 1716-1728, 2015.

31. Leoni G, Neumann PA, Kamaly N, Quiros M, Nishio H, Jones HR, Sumagin R, Hilgarth RS, Alam A, Fredman G, et al: Annexin A1-containing extracellular vesicles and polymeric nanoparticles promote epithelial wound repair. J Clin Invest 125: $1215-1227,2015$

32. Paranavitana $C$, Zelazowska E, Izadjoo $M$ and Hoover D: Interferon-gamma associated cytokines and chemokines produced by spleen cells from Brucella-immune mice. Cytokine 30: 86-92, 2005.

33. Al-Sadi R, Khatib K, Guo S, Ye D, Youssef M and Ma T: Occludin regulates macromolecule flux across the intestinal epithelial tight junction barrier. Am J Physiol Gastrointest Liver Physiol 300: G1054-G1064, 2011.

34. Hirose T, Virnicchi G, Tanigawa A, Naganuma T, Li R, Kimura H, Yokoi T, Nakagawa S, Bénard M, Fox AH and Pierron G: NEAT1 long noncoding RNA regulates transcription via protein sequestration within subnuclear bodies. Mol Biol Cell 25: 169-183, 2014.

35. Zhang Q, Chen CY, Yedavalli VS and Jeang KT: NEAT1 long noncoding RNA and paraspeckle bodies modulate HIV-1 posttranscriptional expression. MBio 4: e00596-12, 2013.

36. Xu P, Becker H, Elizalde M, Masclee A and Jonkers D: Intestinal organoid culture model is a valuable system to study epithelial barrier function in IBD. Gut pii: gutjnl-2017-315685, 2017.

37. Dupaul-Chicoine J, Dagenais M and Saleh M: Crosstalk between the intestinal microbiota and the innate immune system in intestinal homeostasis and inflammatory bowel disease. Inflamm Bowel Dis 19: 2227-2237, 2013.

38. Peterson LW and Artis D: Intestinal epithelial cells: Regulators of barrier function and immune homeostasis. Nat Rev Immunol 14: 141-153, 2014.

39. Kayama H and Takeda K: Regulation of the human gut homeostasis by anti-inflammatory $\mathrm{CD} 14^{+} \mathrm{CD} 163^{\text {high }} \mathrm{CD} 160^{\text {high }}$ myeloid cells. Nihon Rinsho Meneki Gakkai Kaishi 39: 441-447, 2016 (In Japanese).

40. Pott $\mathbf{J}$ and Hornef $\mathrm{M}$ : Innate immune signalling at the intestinal epithelium in homeostasis and disease. EMBO Rep 13: 684-698, 2012.

41. Mao F, Wu Y, Tang X, Kang J, Zhang B, Yan Y, Qian H, Zhang X and $\mathrm{Xu} \mathrm{W}$ : Exosomes derived from human umbilical cord mesenchymal stem cells relieve inflammatory bowel disease in mice. Biomed Res Int 2017: 5356760, 2017.

42. Doe WF and Dorsman B: Chronic inflammatory bowel disease-increased plasminogen activator secretion by mononuclear phagocytes. Clin Exp Immunol 48: 256-260, 1982. 